\title{
Call of Cthulhu: a imagem das criaturas lovecraftianas no jogo Dark Corners of the Earth
}

\section{Call of Cthulhu: the image of the lovecraftian creatures in the game Dark Corners of the Earth}

\author{
Levy Henrique Bittencourt Neto ${ }^{1}$
}

\section{Resumo}

Este artigo tem como objetivo estudar a imagem de três criaturas - Shoggoth, Cthulhu e Dagon baseadas nos livros do escritor H.P. Lovecraft e presentes no jogo Call of Cthulhu: Dark Corners of the Earth. A abordagem principal é sob a perspectiva das categorias fenomenológicas e a semiótica de C. S. Peirce. Através dos nove tipos de signo e das categorias fenomenológicas de primeiridade, secundidade e terceiridade, fez-se uma análise dos componentes visuais das imagens do jogo, em comparação com os escritos de Lovecraft. Através da análise semiótica, percebe-se que o jogo conseguiu, de maneira bem-sucedida, transpor signos fundamentais presentes na literatura de Lovecraft.

Palavras-chave: Lovecraft. Semiótica. Videogames. Fenomenologia.

\begin{abstract}
This article aims to study the image of three creatures - Shoggoth, Cthulhu and Dagon - based on the books of the writer H.P. Lovecraft and present in the game Call of Cthulhu: Dark Corners of the Earth. The main approach is from the perspective of the phenomenological categories and the semiotics of C.S. Peirce. Through the nine types of sign and the phenomenological categories of firstness, secondness and thirdness, an analysis of the visual components of the game images was made, compared to Lovecraft's writings. Through the semiotic analysis, it is noticed that the game succeeded in transposing fundamental signs of the Lovecraft's literature.
\end{abstract}

Key-words: Lovecraft. Semiotics. Videogames. Phenomenology.

1 Doutor em Tecnologias da Inteligência e Design Digital pela Pontifícia Universidade Católica de São Paulo - PUC-SP. E-mail: nikolai.streisky@gmail.com 


\section{Introdução}

A obra de H. P. Lovecraft nunca foi tão popular. Dezenas de escritores foram influenciados por seu Horror Cósmico, não só isso, jogos digitais e RPGs de mesa já exploram o tema há décadas. Existe uma importante contribuição de Lovecraft para o campo da ficção científica e horror, influenciando diversas mídias e novas narrativas. Desta forma, esse artigo tem como objetivo estudar as criaturas do jogo Call of Cthulhu: Dark Corners of the Earth, sob a abordagem da semiótica de C.S. Peirce, e compará-las com trechos dos livros de Lovecraft, tanto os ficcionais quanto os não ficcionais. Com essa abordagem, espera-se demonstrar, através da semiótica, como os signos provenientes da literatura de Lovecraft se corporificaram no jogo digital.

\section{A semiótica e a Fenomenologia de Peirce}

Quando se fala em C.S. Peirce o que vem à mente dos estudiosos é a semiótica, ou lógica, a ciência que se propõe a estudar os signos. De fato, a semiótica "está justo no coração do sistema filosófico de Peirce” (SANTAELLA, 1992, p. 23), mas não se pode esquecer que essa disciplina é apenas um dos pilares de sua catedral filosófica. A própria doutrina dos signos, assim como toda a sua obra, é fundamentada nas descobertas de outra disciplina - a fenomenologia.

Em um dos primeiros ensaios de C.S. Peirce, publicado em 1868, chamado "sobre uma nova lista de categorias", foi postulado ${ }^{2}$ a existência de apenas três elementos fundamentais, que viriam a ser, no futuro, a primeiridade, a secundidade e a terceiridade. Por dezoito anos, essa descoberta fora posta de lado, mas "as pesquisas indutivas, que Peirce realizou nas várias áreas das ciências, foram lhe trazendo, ao longo dos anos, confirmações empíricas para as categorias" (SANTAELLA, 1994, p. 115). Desde o início, portanto, Peirce entendeu a importância de um pensamento livre das amarras das disciplinas tradicionais. Aqui cabe um aviso: a obra de Peirce ainda é fragmentária, suas teorias não foram escritas em ordem cronológica. Mas graças às categorias fenomenológicas, sua arquitetura do conhecimento adquire uma concisão impressionante.

A fenomenologia é a disciplina que estuda e descreve os fenômenos na sua forma mais geral. Peirce considera o fenômeno como "o total coletivo de tudo aquilo que está de alguma forma ou sentido apresentando-se a mente, a propósito daquilo ser correspondente a algo real ou não" (CP 1.284) ${ }^{3}$. Todo e qualquer fenômeno é composto de três categorias irredutíveis e onipresentes: a primeiridade, a secundidade e a terceiridade.

De acordo com Peirce (CP 8.329), "as ideias típicas de primeiridade são as qualidades de sentimento, ou meras aparições, [...] independentemente da forma como elas são percebidas ou lembradas". A primeiridade envolve qualidade, acaso, espontaneidade, originalidade um instante decisivo, único, sem conexão com o passado ou futuro, ou com qualquer outra coisa além de si mesmo. Ela é a categoria da potencialidade infinita, não corporificada, e por isso extremamente fugidia e de difícil abordagem.

A secundidade é a categoria fenomenológica do embate, existência, dualidade, ação-reação, matéria, determinação, reação. Ela "está vinculada às relações que mantém dentro do universo da experiência, sendo estas relações puro fato bruto. Uma experiência privada de objetivo é ação e reação, esforço e resistência". (PEIRCE apud PIRES, 2008, p. 156). Peirce (1975, p. 138) usa como exemplo de secundidade uma pedra caindo. "A queda efetiva da pedra diz respeito simplesmente à pedra e à Terra, naquele instante. Tal é o que se denomina reação. E tal é a existência, modo de ser daquilo que reage

\footnotetext{
${ }^{2}$ Ver o ensaio original em CP 1.545 - 559.

${ }^{3}$ Será usada a referência usual a esta obra: $\mathrm{CP}$ indica The Collected Papers of Charles Sanders Peirce; o primeiro número corresponde ao volume e o segundo, ao parágrafo.
} 
com outras coisas". O filósofo (PEIRCE, 1975, p. 140) também considera secundidade qualquer relação diádica que não envolva um terceiro.

A terceiridade é a categoria da mediação entre o primeiro e o segundo (palavras relativas às outras categorias), tempo, conceitos, generalizações e pensamentos. "Através da generalização do fato bruto, ela proporciona a representação das circunstâncias em que poderão vir a ser. Irá procurar estabelecer as leis gerais que determinarão a conduta autocontrolada para sua efetivação". (PIRES, 2008, p. 157). Qualquer conceito, cognição, lei ou hábito é um terceiro. Esse texto, as regras gramaticais e o alfabeto são alguns exemplos da terceiridade em funcionamento. É justamente nessa categoria fenomenológica que o pensamento peirceano se diferencia das demais correntes semióticas e semiológicas. $\mathrm{Na}$ verdade, essa é a grande diferença entre Peirce e as diversas correntes filosóficas de caráter dual:

Para mim, que durante quarenta anos examinei a questão de todos os pontos de vista que pude descobrir, a insuficiência da secundidade para abranger tudo que vai por nosso espírito é tão evidente que quase não sei como principiar para persuadir disso qualquer pessoa que ainda não esteja convencida. [...]. Se tomarmos qualquer relação triádica ordinária, nela sempre divisaremos um elemento mental. (PEIRCE, 1975, p. 140).
A semiótica, ou lógica, é a teoria pela qual C.S. Peirce ficou mais conhecido. Um signo (ou representamen) é aquilo que "representa algo para alguém. Dirige-se a alguém, isto é, cria, na mente dessa pessoa, um signo equivalente, ou talvez um signo mais desenvolvido. Ao signo assim criado denomino interpretante do primeiro signo" (PEIRCE, 2003, p. 46). Lucia Santaella (2004, p. 189), usa uma bela metáfora para afirmar que o signo é "a matéria-prima de que o pensamento e o raciocínio são feitos". Assim, entende-se o signo não só da própria arte, da comunicação, da linguagem, mas também como matéria prima de todo pensamento e percepção.

\section{Gramática Especulativa: os Nove Tipos de Signos}

Os nove tipos signos são divididos, de acordo com as categorias fenomenológicas, em três tricotomias ${ }^{4}$ : o signo em relação a ele mesmo; em relação ao objeto dinâmico; em relação ao interpretante final. "A primeira, conforme o signo em si mesmo for uma qualidade, um existente concreto ou uma lei geral". (PEIRCE, 2003, p. 51). A semiótica é dividida em três $\operatorname{ramos}^{5}$, mas o presente estudo optou-se em se concentrar na Gramática Especulativa, que trata das divisões dos signos.

Quadro 1 - Os nove tipos de signo e suas respectivas categorias fenomenológicas

$\begin{array}{cccc} & \text { Primeiridade } & \text { Secundidade } & \text { Terceiridade } \\ \text { O signo em relação ao }- & \text { Signo } & \text { Objeto Dinâmico } & \text { Interpretante Final } \\ \text { Primeiridade } & \text { Qualissigno } & \text { Ícone } & \text { Rema } \\ \text { Secundidade } & \text { Sinsigno } & \text { Índice } & \text { Dicente } \\ \text { Terceiridade } & \text { Legissigno } & \text { Símbolo } & \text { Argumento }\end{array}$

Fonte: Autor. 
Se ele for uma qualidade, será um qualissigno, isto é, "funciona como signo por intermédio de uma primeiridade da qualidade, qualidade como tal, possibilidade abstraída de qualquer relação empírica espaço-temporal da qualidade com qualquer outra coisa". (SANTAELLA, 2008, p. 99). Nessa tricotomia, o qualissigno é um signo de primeiridade. Apesar dele só atuar como signo quando é corporificado em algum existente, "essa corporificação nada tem a ver com seu caráter de como signo". (PEIRCE, 2003, p. 52).

Se ele for um existente, será um sinsigno. Segundo Santaella (2008, p. 100), o prefixo sin sugere "a idéia de um único, singular, aqui e agora. Peirce também se refere ao sinsigno como um objeto da experiência direta. Assim, qualquer coisa que compele nossa atenção é, na sua insistência, um segundo em relação à atenção compelida". Por seu caráter existencial, um sinsigno é um signo de secundidade, que envolve um ou vários qualissignos, "mas estes qualissignos são de um tipo particular e só constituem um signo quando realmente se corporificam". (PEIRCE, 2003, p. 52).

O legissigno é um signo de lei, hábito, generalização e tempo. "Todo o signo convencionalé um legissigno (porém a recíproca não é verdadeira). [...] Todo o legissigno significa através de um caso de sua aplicação, que pode ser denominado réplica". (PEIRCE, 2003, p. 52). A réplica é um sinsigno especial, que corporifica a lei num caso particular. É o legissigno que dá significado a ocorrências singulares que se conformam numa regra ou lei geral. Portanto, o legissigno requer sinsignos para seu devido funcionamento. Por seu caráter geral, um legisigno é um signo de terceiridade.

A segunda tricotomia se refere ao signo em relação ao seu objeto dinâmico, podendo ser um ícone, índice ou símbolo. Um ícone é um signo se "ele se assemelhar ao seu objeto e se a qualidade ou caráter, no qual essa semelhança está fundada, pertencer ao próprio signo, quer seu objeto exista ou não". (SANTAELLA, 2008, p. 110). O ícone é um tipo de signo de primeiridade.
O índice é um tipo de signo de existência real, que aponta, indica algo para alguma coisa. Segundo Lucia Santaella (2008, p. 123) se houver uma "ligação de fato, dinâmica, por mais rudimentar que seja, aí haverá traço de indexicalidade. Esse traço significa que é a conexão física entre signo e objeto que dá capacidade para o índice agir como signo, independente de ser interpretado ou não". O índice é um signo de secundidade pura, pois faz parte da tricotomia do objeto dinâmico e ocupa a posição de secundidade no interior dessa tricotomia.

O símbolo é um signo convencional, que gera um interpretante de acordo com padrões gerais préestabelecidos. Dessa forma, o símbolo é

“[...] apenas uma mediação, um meio geral para o desenvolvimento de um interpretante. Ele constitui um signo pelo fato de que será usado e interpretado como tal. É no interpretante que reside sua razão de ser signo. Seu caráter está na sua generalidade e sua função é crescer nos interpretantes que gerará". (SANTAELLA, 2008, p. 132).

A última tricotomia corresponde ao signo em relação ao interpretante final. O rema "é um signo que é interpretado por seu interpretante final como representando alguma qualidade que poderia estar corporificado em algum objeto possivelmente existente". (SANTAELLA, 2008, p. 144). Em outras palavras, o efeito gerado, isto é, o rema, será de um tipo possível, não necessariamente corporificado, que poderia representar alguma classe de objeto.

O dicente é um signo que representa, para o interpretante, uma existência real. Assim, ele é um signo que deverá "ser interpretado pelo seu interpretante final como propondo e veiculando alguma informação sobre um existente, em contraposição ao ícone, por exemplo, do qual só se pode derivar informação". (PEIRCE apud SANTAELLA, 2008, p. 146).

Por fim, o argumento é tipo de signo que deverá gerar um efeito como uma "lei, regra reguladora, ou princípio guia. [...] Isto é, a lei segundo a qual 'a passagem de todo o conjunto das premissas 
para as conclusões tende a ser verdadeira' (2.203)" (SANTAELLA, 2008, p.147). Assim, o argumento deverá gerar um efeito que, para seu interpretante, se conforma a um princípio guia.

Para demonstrar o funcionamento das categorias e tipos de signo apresentados, analisou-se a imagem de três criaturas do jogo Call of Cthulhu - Dark Corners of the Earth. A escolha se deve pelo fato de que o jogo está intimamente ligado à literatura de H.P. Lovecraft, por isso é um bom exemplo de como os signos culturais transitam pelas mídias. E com o auxílio das teorias de Edgar Morin e Ivan Bystrina tentou-se entender o sentido das imagens e da literatura de Lovecraft, projetadas num jogo digital do século XXI.

\section{Lovecraft, Loucura, Vida e Morte}

Como o próprio nome sugere, Call of Cthulhu: Dark Corners of the Earth é baseado nos contos e romances de Howard Phillips Lovecraft (18901932) ${ }^{6}$. Natural da cidade de Providence, nos Estados Unidos, não alcançou sucesso em vida, mas atualmente é reconhecido como um dos grandes nomes da literatura fantástica do século XX. Em suas obras, não existe demarcação entre o bem e o mal, apenas o caos zombeteiro e criaturas insensíveis aos humanos.

Lovecraft resumiu seu pensamento filosófico pelo termo adequado "indiferentismo cósmico". Essa é, ao mesmo tempo, uma postura metafísica e ética; ou melhor, a ética é inerente à metafísica. A ciência moderna nos diz que - o que quer que seja a "coisa" real da natureza - a Terra é apenas uma minúscula mancha de tinta na vasta extensão do cosmos. Toda a história da vida humana é um incidente momentâneo na agitação incessante de elétrons que constitui um universo eterno e infinito. (JOSHI, 2017, p. 175).
Os monstros lovecraftianos são criaturas vindas de outras dimensões, ou de tempos ancestrais, numa época anterior a existência de qualquer vertebrado conhecido. "[Lovecraft] povoa seu universo literário de monstros e demônios, de todo um Panteão de deuses terrestres e extraterrestres interligados numa saga mitológica que perpassa várias de suas narrativas". (LOVECRAFT, 2001, p. 4). A coletânea desse panteão de criaturas e casos extraordinários ficou conhecida como Mitos de Cthulhu.

Quando Lovecraft fala que "a emoção mais forte e mais antiga do homem é o medo, e a espécie mais forte e mais antiga de medo é o medo do desconhecido" (LOVECRAFT, 1987, p. 01), Dentro da perspectiva materialista do autor esse "medo do desconhecido" seria um medo daquilo que não é necessariamente inexplicável do ponto de vista científico. Seria o medo provocado pela conscientização do quão pouco o ser humano sabe sobre a realidade. A inferência de que podemos vir a descobrir verdades que não serão agradáveis seria a essência do Horror Cósmico. (DUTRA, 2015, p. 180).

Os protagonistas de Lovecraft são impotentes perante os horrores cósmicos, a derrota é certa, se eles não morrem de forma violenta e misteriosa, acabam confinados em um sanatório - como no jogo - ou passam o resto de suas vidas traumatizados pelos acontecimentos. Percebe-se que a loucura e a morte são elementos muito presentes nas obras de Lovecraft. "Chamamos loucura à conjunção da ilusão, do descomedimento, da instabilidade, da incerteza entre o real e imaginário, do erro, da desordem". (MORIN, 1975, p. 116-117). Como a mente humana reagiria a coisas que são totalmente alienígenas, disformes, aterradoras? A loucura é como uma reação a esses elementos completamente

6 Recomendo o acesso ao site http://www.hplovecraft.com que contém toda a obra de H.P. Lovecraft, lista de criaturas, a biografia do autor, entre outras informações interessantes. Praticamente tudo sobre Lovecraft pode ser encontrado neste site. Em inglês. 
anômalos da realidade. "Seria concebível que os esforços do subconsciente para preencher um vazio intrigante com pseudomemórias poderiam originar estranhas fantasias da imaginação?" (LOVECRAFT, 2007, p. 160).

"Convencido da transitoriedade e insignificância do homem em meio ao vasto cosmos, sua visão do fantástico perturba nossa realidade antropocêntrica. O medo não é mais causado diretamente pelo encontro com elementos mórbidos e macabros (cadáveres, fantasmas ...), mas sim pela consciência de nossa situação vulnerável no mundo". (RUIZ; BIENVENIDO, 2015, p. 101)

A vida e a morte são o grande duplo da existência de qualquer ser vivo. "No início da cultura humana a oposição mais importante era vida-morte. E toda a estrutura dos códigos terciários ou culturais se desenvolve a partir dessa oposição básica". (BYSTRINA, 1995, p. 6). Para Bystrina, os códigos terciários são produtos da cultura, por exemplo, um livro, um quadro, ou mesmo um jogo baseado nos livros de Lovecraft. Há um problema assimétrico entre a vida e a morte, já que a morte sempre supera a vida. Uma maneira de normalizar essa assimetria é a criação de uma segunda realidade, "a realidade imaginária, que se utiliza da magia" (BYSTRINA, 1995, p. 6), em oposição a primeira realidade, em outras palavras, o mundo material. "O artista cria a partir do tesouro dos mitos populares, das lendas, dos contos de fadas" (BYSTRINA, 1995, p. 22).

Há uma relação íntima entre o sonho e o mito, como afirma Bystrina (1995, p. 13), "só tardiamente o homem passou a distinguir as duas realidades. [...] As estruturas básicas do sonho se repetem, ao menos em parte, nos devaneios, nas fantasias da vigília". No homem primitivo, o sonho era tão real quanto o nascer do sol. Mesmo tendo separado essas duas realidades, o mundo dos sonhos deixou sua marca de forma permanente na psique humana. "É preciso considerar a proliferação onírico-fantástica, não como uma vaga superestrutura, mas sim [...] como um aspecto primordial do funcionamento cerebral do sapiens, tendo nele um enorme desperdício, bem como um princípio de criatividade". (MORIN, 1975, p. 129). A criação dos mitos é grandemente influenciada pelos sonhos, e, por conseguinte, influencia a própria cultura humana.

"O fenômeno do sonho também ajudou a construir a noção de um mundo irreal ou espiritual; e, em geral, todas as condições da vida selvagem primitiva conduziam com tanta força a um sentimento do sobrenatural, que não nos deve espantar o quanto a própria essência hereditária do homem ficou saturada de religião e superstição". (LOVECRAFT, 2008, p. 15).

É interessante notar que, segundo Morin (1975, p. 107), há uma ligação entre a "imagem, o imaginário, a magia, o rito". Isso porque a imagem tem a característica de um signo duplo, ela está no lugar do objeto representado, como uma fotografia de uma paisagem está no lugar da paisagem. Flusser (2002, p. 7) afirma que "imaginação é a capacidade de fazer e decifrar imagens". Se há uma ligação entre imagem, imaginário, magia e rito, é possível perceber que tais elementos cumprem uma função: "um aparelho mitológico-mágico que emerge no sapiens se encontra mobilizado para enfrentar a morte". (MORIN, 1975, p. 103). Assim, tanto Ivan Bystrina quanto Edgar Morin apontam para uma mesma direção: todas as produções culturais humanas têm o propósito de vencer a morte, seja este propósito metafórico ou não.

\section{Da literatura de H.P. Lovecraft ao jogo Call of Cthulhu: Dark Corners of the Earth}

Com base nesses pressupostos, pode-se apresentar o objeto a ser estudado: o jogo para computador Call of Cthulhu - Dark Corners of the Earth, lançado em $2006^{7}$. O jogo é single player, do

7 Antes de ter uma versão para PC, o jogo havia sido lançado, em 2005, para o primeiro Xbox. 
tipo FPS (First Person Shooter) $)^{8}$, isto é, a visão é em primeira pessoa - com a câmera na posição dos olhos - como pode ser visto no screenshot ${ }^{9}$ abaixo:

Imagem 1 - Exemplo da visão em primeira pessoa (first person shooter) no jogo Call of Cthulhu

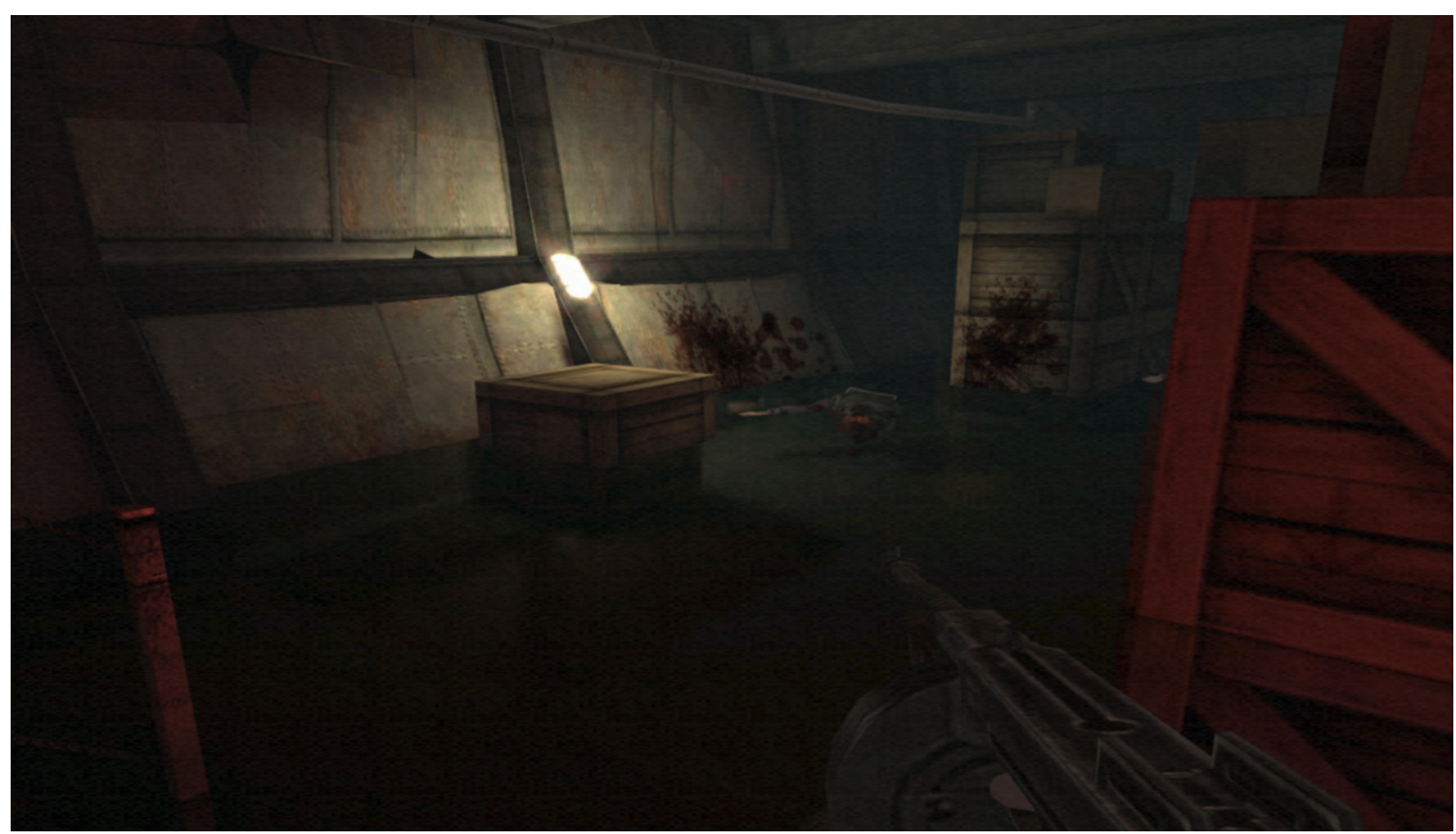

Fonte: Do autor - Screenshot.

O jogo começa em 1915, época em protagonista da história, Jack Walters, era um policial. Ele investigava um caso estranho, relacionado a um culto religioso na cidade de Boston. Esse caso afetou a mente de Walters de tal modo que ele tinha momentos de lucidez e loucura, e teve que ficar internado no Sanatório da cidade de Arkham $^{10}$, por apresentar sintomas de esquizofrenia e dupla personalidade. Sua sanidade só fora restabelecida por completo seis anos depois.

Trabalhando como detetive particular, Walters recebe uma ligação do governo a respeito de um sequestro ocorrido na pequena cidade de Innsmouth. A história toda é contada em flashback, pois logo no começo do jogo assiste-se a uma cinematics $^{11}$ mostrando o investigador, após o caso de Innsmouth, cometer suicídio no sanatório.

Ao longo da narrativa, Walters vai se aprofundando nos mistérios que jazem sob a cidade de Innsmouth. Existem muitas referências visuais no jogo que se reportam à Lovecraft, como os moradores da cidade de Innsmouth, com sua aparência bizarra por conta de uma suposta doença local. Ou então a raça ancestral de viajantes do

8 Tradução aproximada: Jogo de tiro em primeira pessoa.

9 Screenshot é um termo que se usa para se designar um "fotograma" do jogo. Ele é conseguido apertando a tecla Print Screen e utilizando qualquer software de leitura de imagens. Alguns jogos possuem esse recurso neles mesmos, sem precisar recorrer a um outro programa para obter a imagem.

${ }^{10}$ Foi a criação de Lovecraft que inspirou o nome do famoso hospício das histórias em quadrinhos do Batman: Arkham Asylum.

${ }^{11}$ Cinematics são os vídeos, algumas vezes interativos, presentes em jogos eletrônicos. 
tempo, a Grande Raça de Yith, responsáveis diretos pelos seis anos de instabilidade mental de Walters. Optou-se por analisar três das mais icônicas criaturas de Lovecraft presentes no jogo: Shoggoth, Dagon e

\section{Signos de Primeiridade: Shoggoth}

Imagem 2 - Screenshot de um dos ângulos do Shoggoth

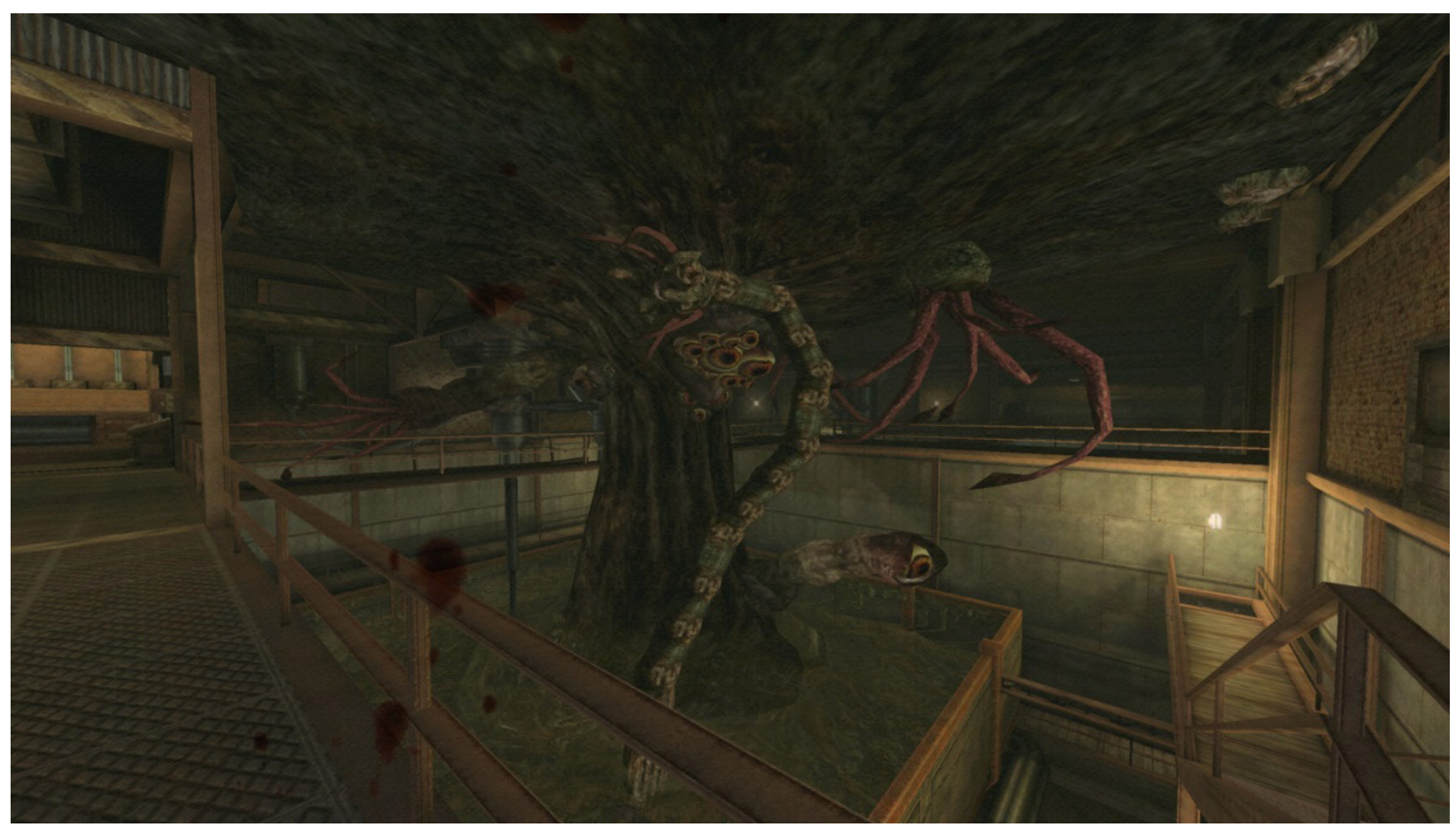

Fonte: Valve (2016).
"Era uma coisa terrível, inacreditável, mais vasta que qualquer metrô - um amontoado disforme de bolhas protoplasmáticas, ligeiramente luminescente, com miríades de olhos temporários, que se formavam e se desfaziam como pústulas de luz esverdeada" (LOVECRAFT, 2011, p. 802).

De todas as criaturas escolhidas, o Shoggoth é a mais anômala de todas. Não é nem de longe antropóide, ou sequer uma forma física determinada. Como um ser em constante mutação, a primeiridade é a categoria fenomenológica mais intensa nessa criatura: formas indeterminadas, cores, movimentos e comportamento errático. Não há como prever a próxima ação que tal criatura alienígena é capaz de
Cthulhu. A cada uma das criaturas se atribuiu uma categoria fenomenológica predominante e seus respectivos signos. 
do jogo reproduz com certa fidelidade a descrição do autor. "Onde termina a loucura e começa a realidade? Será possível que este meu recente pavor seja pura ilusão?" (LOVECRAFT, 2005, p. 117).

Os qualissignos são muito eloquentes nessa enorme criatura: amorfa, apenas tons, cores, sons e texturas mutantes esverdeadas. Olhos brilhantes, semelhantes a pústulas alaranjadas, perscrutam por todos os lados do monstro. As qualidades expressas no jogo são semelhantes, apesar de menos intensas, do que a descrição de Lovecraft.

Os ícones dessa criatura propiciam uma analogia em relação ao seu tamanho, maior que qualquer carro de metrô, e quase tão rápido quanto. No livro Nas Montanhas da Loucura, os protagonistas só conseguem escapar do Shoggoth porque ele se distraí com uma outra presa. Rápido e grande, é só através dos ícones que é possível traçar relações de semelhança, pois as características morfofisiológicas não são estáveis, tampouco seu comportamento ou hábitos podem ser definidos claramente. Há também a já citada relação icônica entre a figura do Shoggoth e a obra de Lovecraft justamente a relação que o jogo digital estabelece com a literatura. Desta forma, percebe-se que o ícone é um tipo de signo importante na transmissão de informação entre mídias diferentes.

Exatamente pela dificuldade em se estabelecer uma lei, o rema é um signo muito ativo nessa criatura. Não se sabe absolutamente nada sobre os hábitos da criatura, mas percebe-se que ela é grande e poderosa, pois foram criadas pela raça dos Grandes Antigos como máquinas biológicas para construção de gigantescos complexos. Dotados de uma inteligência rudimentar, conseguiram se voltar contra seus criadores, destruindo seu império na Terra ancestral. O shoggoth é uma criatura enorme nas potencialidades, mas simples nas suas efetivações, pois tudo o que fez foi destruir os seus senhores. O shoggoth, por suas características anômalas, é a criatura de primeiridade por excelência.

Signos de Secundidade: Dagon

Imagem 3 - Embate do protagonista contra o deus Dagon

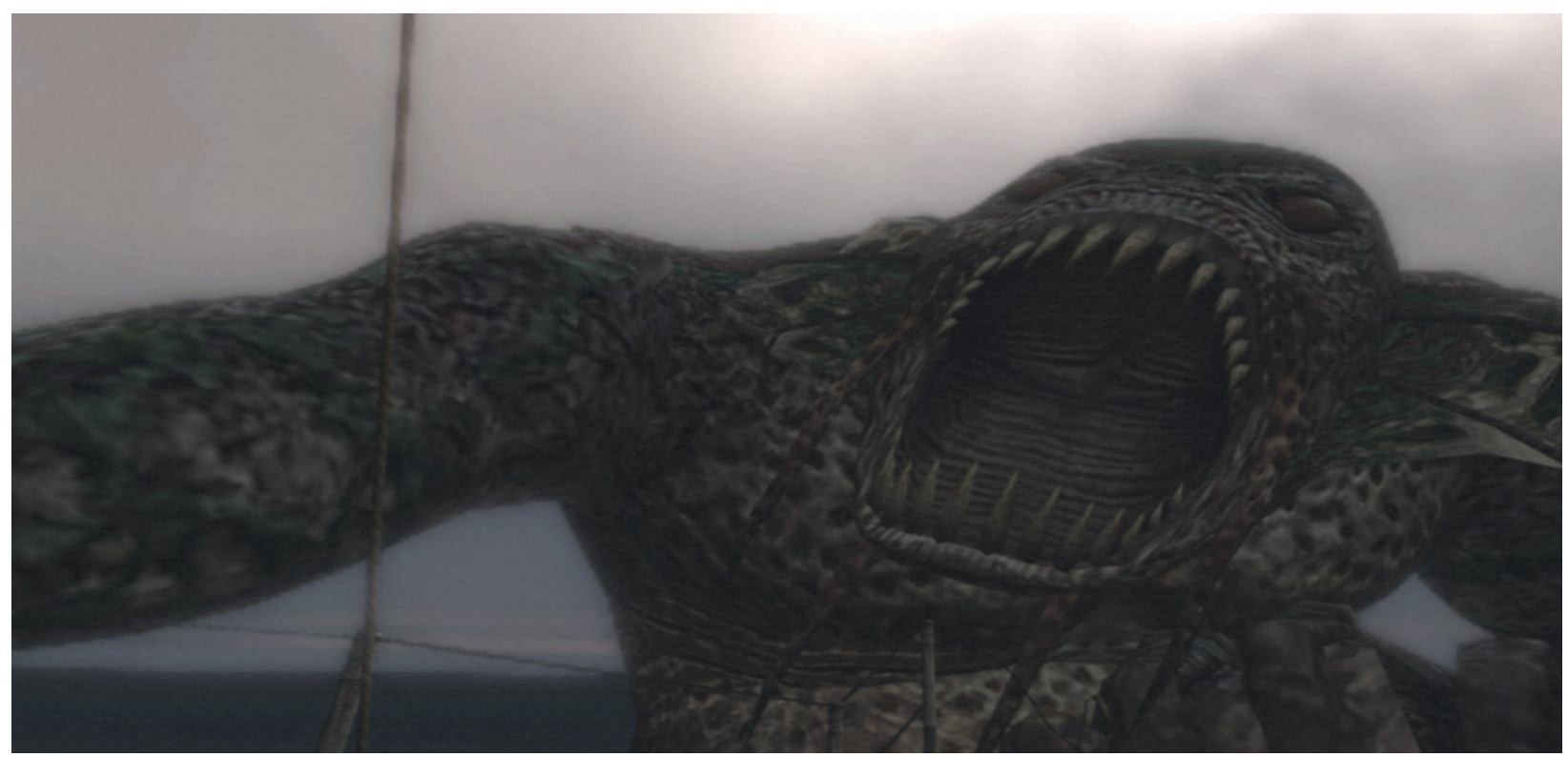

Fonte: Do autor - Screenshot. 
"Enorme, polifêmica e repugnante, ela disparou como o monstro fabuloso de um pesadelo para o monolito, ao redor do qual arrojou seus gigantescos braços escamosos, enquanto inclinava a cabeça horripilante, produzindo sons ritmados" (LOVECRAFT, 2005, p. 40).

Dentre todas as criaturas desse capítulo, Dagon é a única divindade que de fato existiu, sendo um deus-peixe adorado pelos filisteus. Dagon também é citado na Bíblia (BÍBLIA, 2016), em Juízes 16:23 $3^{12}$, 1 Samuel 5:2 $2^{13}$ e $7^{14}$ e 1 Crônicas 10:10 A aparência de Dagon é a de um ser antropóide com características de criaturas marinhas, e não por acaso era adorado por um povo que vivia na costa leste do Mediterrâneo. No jogo, o protagonista entra em batalha com a divindade, usando um canhão do navio em que estava para derrotá-lo.

De certa forma, algumas das criaturas lovecraftianas foram inspiradas em divindades existentes, como Hypnos, o deus grego do sono, presente em alguns de seus contos. Dagon também foi retirado diretamente de uma mitologia real que teve seu lugar de adoração num determinado tempo da história humana. A Lovecraft coube contextualizá-lo no século XX. Os adoradores de Dagon, na obra de Lovecraft, são os moradores da cidade de Innsmouth. A maior inspiração do jogo $C C D C E$ são os contos Dagon e A Sombra sobre Innsmouth, inclusive boa parte do jogo se passa na cidade de Innsmouth.
A secundidade é mais presente na criatura pelo simples fato de que é uma divindade que um dia existiu. Existência e passado são alguns dos aspectos importantes da secundidade. No contexto do jogo, a força bruta da secundidade está bem explícita em Dagon. Ao contrário do esparso e fragmentário culto a Cthulhu, o culto ao Deus Peixe é concentrado num lugar. O próprio Dagon, ao contrário de Cthulhu, está presente fisicamente no cotidiano de seus adoradores.

Como sinsigno, Dagon é um ser de existência real, um dia fora adorado como um deus, e no contexto das obras de Lovecraft é uma divindade ativa e presente. É uma força existente que faz parte do cotidiano dos moradores da cidade de Innsmouth, que exige sacrifícios e cultos constantes.

Dagon é um índice das divindades e culturas ancestrais marítimas, com suas características físicas lembrando um peixe antropoide. A divindade indica a relação do povo com os horrores submersos. Inclusive, os moradores de Innsmouth são acometidos com uma doença que aos poucos os transforma em versões em miniatura do titã marinho.

O dicente é bem claro em Dagon. No jogo, o protagonista enfrenta a criatura em um combate, usando o canhão do navio como arma. É um existente, que exige um embate de forças opostas, o canhão e a criatura. Não fornece nenhuma informação acerca de hábitos e comportamento, apenas a força bruta do combate pela sobrevivência.

\footnotetext{
${ }^{12}$ Então os príncipes dos filisteus se ajuntaram para oferecer um grande sacrifício ao seu deus Dagom, e para se alegrarem, e diziam: Nosso deus nos entregou nas mãos a Sansão, nosso inimigo.

${ }^{13}$ Tomaram os filisteus a arca de Deus, e a colocaram na casa de Dagom, e a puseram junto a Dagom.

${ }^{14}$ Vendo então os homens de Asdode que assim foi, disseram: Não fique conosco a arca do Deus de Israel; pois a sua mão é dura sobre nós, e sobre Dagom, nosso deus.

${ }^{15}$ E puseram as suas armas na casa do seu deus, e a sua cabeça afixaram na casa de Dagom.
} 
Signos de Terceiridade: Cthulhu

Imagem 4 - Estátua de Cthulhu em R'lyeh

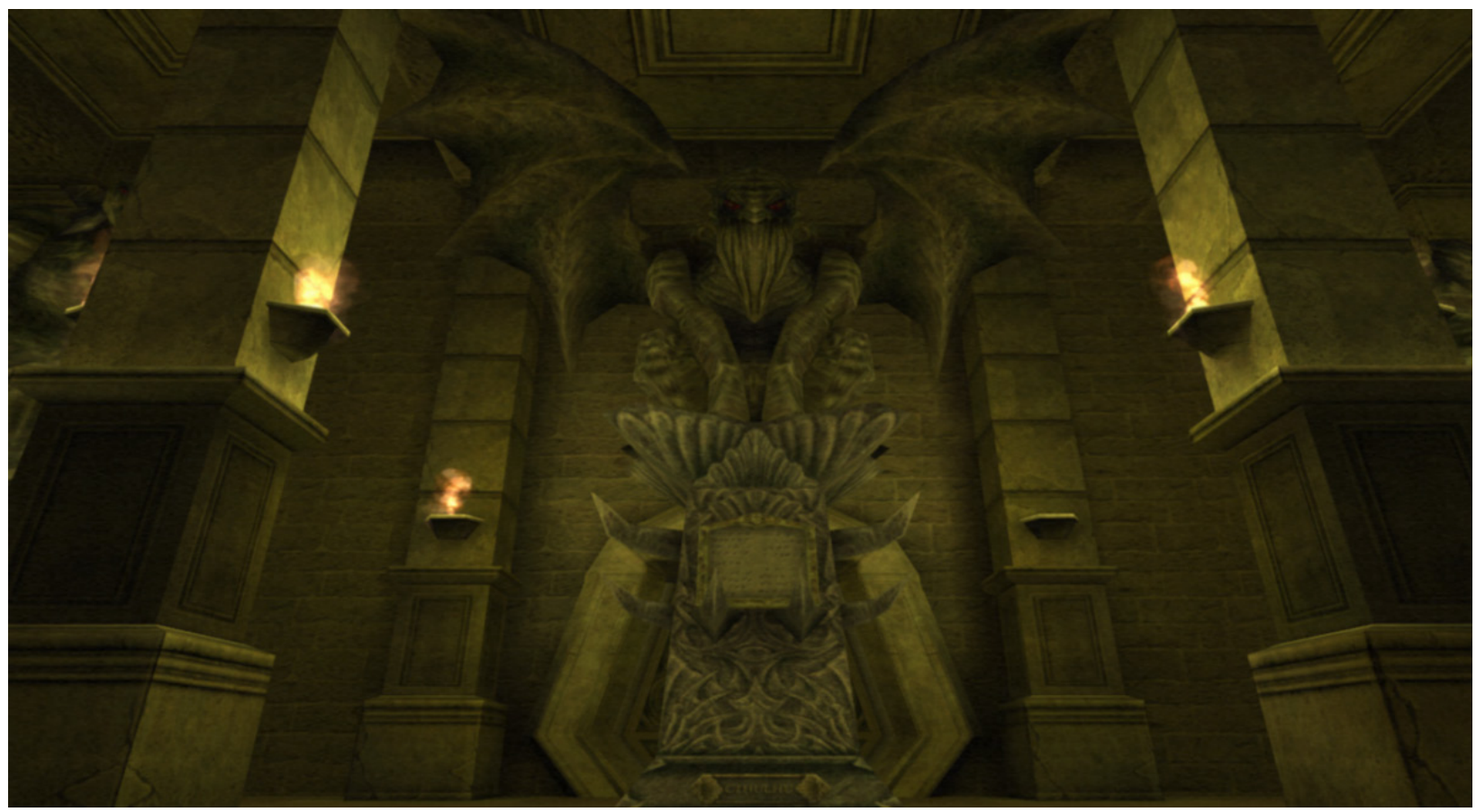

Fonte: Do autor - Screenshot.

Se digo que minha imaginação um tanto extravagante forjou imagens simultâneas de um polvo, um dragão e uma caricatura humana, não serei infiel ao espírito da coisa. Uma cabeça carnuda e tentaculada coroava um corpo grotesco, coberto de escamas, com asas rudimentares, mas era o contorno geral do conjunto que o tornava mais aterrorizante. (LOVECRAFT, 2011, p. 357).

De todas as criaturas de Lovecraft, sem dúvida Cthulhu é a mais famosa, a tal ponto de reunir todas as criações do autor sob seu nome. O jogo se chama Call of Cthulhu, que também é o nome do mais famoso conto do autor. Mesmo assim, a criatura não aparece no jogo, apenas sua estátua, como mostra o screenshot acima. Cthulhu é um ser ancestral que se comunica com os humanos através de sonhos (LOVECRAFT, 2011). Ele é uma espécie de deus para os humanos, e uma espécie de sacerdote para os seus pares. Bilhões de anos atrás, quando a Terra tinha apenas formas simples, Cthulhu chegou ao planeta e fundou a mítica cidade de R'lyeh.

Disseram ser adoradores dos Grandes Antigos, que viveram eras antes que houvesse homens, e que chegaram a um mundo jovem vindos do céu. Os Antigos já haviam sucumbido, dentro da terra e no fundo do mar; mas seus corpos mortos contaram seus segredos em sonhos para os primeiros homens, que formaram um culto que não havia morrido. Este foi o culto, e os prisioneiros disseram que ele sempre existiu e que sempre existirá, escondido em lugares distantes e obscuros em todo o mundo, até o momento em que o grande sacerdote Cthulhu, de sua casa escura na poderosa cidade submersa de R'lyeh, deve se levantar e trazer de novo a Terra sob seu domínio. Quando as estrelas estiverem alinhadas Cthulhu chamará, e o seu culto secreto estará sempre a espera para libertálo. (LOVECRAFT, 2011, p. 366). 
É através dos sonhos que o sacerdote Cthulhu se comunica, e esses sonhos reverberaram ao longo dos milênios na psique humana, moldando não só a cultura, mas também todo o complexo imaginário do Homo sapiens. "O onirismo [...] prolifera, no homem, sob formas de fantasias, do imaginário, da imaginação" (MORIN, 1975, p. 115). A terceiridade é a categoria fundamental para o entendimento dos efeitos que o Cthulhu causa. Através dos tempos, portanto, um continuum, sua influência reverbera através de signos na cabeça dos humanos. Tempo e mediação são aspectos da terceiridade, assim como os códigos pré-estabelecidos que compõe qualquer religião, como o culto secreto do deus alienígena.

O legissigno está muito presente, pois através de sonhos que reverberam na cabeça dos fiéis, em outras palavras, réplicas dos legissignos que emanam do deus Cthulhu, que ele exerce a lei ou regra geral que se conformará em casos particulares - seus seguidores. Não é muito diferente de qualquer outra religião, nota-se. Toda a religião possui um conjunto de normas e dogmas, que são como legissignos para os seguidores de tal doutrina. Por sua vez, os seguidores atuam como sinsignos do tipo especial - réplicas do legissigno, isto é, vivem o cotidiano, transformam as leis imateriais da igreja em ações no mundo real.

O símbolo está corporificado (sinsignos indiciais, portanto) em duas instâncias, nos caracteres antigos, no canto inferior esquerdo da imagem, e na própria estátua. Enquanto os caracteres representam a linguagem e cultura da criatura ancestral, sua estátua simboliza o poder e a imanência que Cthulhu exerce sobre o mundo. Ele não está presente fisicamente, como Dagon, nem possui uma corporificação anômala e caótica, como o Shoggoth. O sacerdote Cthulhu conta com outro tipo de influência, pois é através de diversos símbolos, entre eles a estátua, que o seu poder é mantido. Códigos, ritos, cerimônias, enfim, é através de símbolos que Cthulhu governa.

Por fim, o argumento, um signo de lei, é justamente o que fará o deus adormecido despertar.
Através de determinados ritos simbólicos levados adiante pelos seguidores de Cthulhu, espera-se o despertar da criatura na ocasião de um alinhamento Cósmico ainda por acontecer. Nota-se claramente o signo de lei agindo, porque é preciso um conjunto de normas gerais para que o efeito esperado aconteça. Mais do que isso, é através dos sonhos que a comunicação entre Cthulhu e seus seguidores acontece. São nos sonhos que o sacerdote passa o conhecimento e as leis de sua religião, para que um dia, Cthulhu possa despertar de seu sono. Não é à toa que Lovecraft, no livro de não-ficção "o horror sobrenatural em literatura", coloca o reino dos sonhos como o gerador de toda a superstição humana, pois os "sonhos e fantasias produzem combinações novas, estranhas, surpreendentes, mistura de incoerência e de coerência". (MORIN, 1975, p. 127). O mito de Cthulhu é uma metáfora inquietante dos mistérios ancestrais das influências invisíveis, vindas de épocas imemoriais na história do ser-humano... Ou mesmo do pré-humano.

\section{Considerações Finais}

O jogo Call of Cthulhu: Dark Corners of the Earth consegue de maneira bem-sucedida transcrever os horrores literários de Lovecraft, sendo fiel a aparência das criaturas analisadas, Shoggoth, Dagon e Cthulhu. Shoggoth, pela sua natureza indeterminada e amorfa, corresponde à primeiridade. Dagon, por ser um deus atuante, tanto no jogo quanto na literatura de Lovecraft, foi relacionado à secundidade. E, por fim, Cthulhu, o deus morto, aparece no jogo apenas através de representações, como as estátuas em R'lyeh e as menções ao seu culto, portanto, relacionado mais fortemente aos signos de terceiridade.

\section{Referências}

BÍBLIA. Português. Bíblia on-line. Disponível em: https://www.bibliaonline.com.br. Acesso em: 9 out. 2016.

BYSTRINA, I. Tópicos de semiótica da cultura. São Paulo: Cisc, 1995. Pré-print. 
DUTRA, D. I. O horror sobrenatural de H.P. Lovecraft: teoria e praxe estética do horror cósmico. 2015.260 f. Tese (Doutorado em Literatura Comparada) - Universidade Federal do Rio Grande do Sul, Porto Alegre, RS, 2015.

FLUSSER, V. Filosofia da caixa preta: ensaios para uma futura filosofia da fotografia. Rio de Janeiro: Relume Dumará, 2002.

JOSHI, S. T. The weird tale. Seatle: Sarnath Press, 2017.

LOVECRAFT, H. P. A cor que caiu do céu. 2. ed. São Paulo: Iluminuras, 2007.

LOVECRAFT, H. P. A maldição de Sarnath. 2. ed. São Paulo: Iluminuras, 2001.

LOVECRAFT, H. P. Dagon. 2. ed. São Paulo: Iluminuras, 2005.

LOVECRAFT, H. P. O horror sobrenatural em literatura. São Paulo: Iluminuras, 2008.

LOVECRAFT, H. P. The complete fiction. New York: Barnes \& Noble, 2011.

MORIN, E. O enigma do homem: para uma nova antropologia. Rio de Janeiro: Zahar Editores, 1975.

PEIRCE, C. S. Semiótica e filosofia. São Paulo: Cultriz, 1975.
PEIRCE, C. S. Semiótica. São Paulo: Perspectiva, 2003.

PEIRCE, C. S. The collected papers of Charles Sanders Peirce. Charlottesville, VA: Intelex Corporation, 1994.

PIRES, J. B. Vida e obra de Charles Sanders Peirce e as bases para o estudo da linguagem fotográfica. Revista Discursos Fotográficos, Londrina, v. 4, n. 4, p. 145-160, 2008.

RUIZ, M. F.; BIENVENIDO, H. P. Universos fantásticos de inspiración Lovecraftiana en videojuegos survival horror: Un estudio de caso de p.t (silent hills). Brumal: revista de investigación sobre lo fantástico, Barcelona, v. 3, n. 1, p. 95-118, 2015.

SANTAELLA, L. A assinatura das coisas: Peirce e a literatura. Rio de Janeiro: Imago, 1992.

SANTAELLA, L. A teoria geral dos signos. São Paulo: Pioneira, 2008.

SANTAELLA, L. Estética: de Platão a Peirce. 2. ed. São Paulo: Experimento, 1994.

SANTAELLA, L. $O$ método anticartesiano de $C$. $S$. Peirce. São Paulo: Editora UNESP, 2004.

VALVE. Shoggoth. Disponível em: https:// s t e a m c o m m unity. com/s haredfile s/ filedetails/?id=780930632. Acesso em: 1 out. 2016.

Recebido em: 08 ago. 2018

Aceito em: 10 abr. 2019 
